\title{
Environmental Hydrochemical Characteristics of a Dam Site of a Hydropower Station and its Influence on the Project
}

\author{
Ze Wang ${ }^{1 *}$ \\ ${ }^{1}$ College of Chemistry and Molecular Sciences, Wuhan University, Wuhan, Hubei, 430072, China
}

\begin{abstract}
Environmental water's corrosion evaluation of concrete (structure), steel bars and steel structures in reinforced concrete structures is an item of engineering investigation. Therefore, environmental water samples are used for water chemical composition testing during the investigation and carried out according to regulations. Evaluation is very necessary. Taking the Lai Hydropower Station dam site as an example, through the test results of the chemical composition of the water samples, the environmental water and engineering-related chemical characteristics are analyzed, and the corresponding corrosiveness evaluation is carried out according to the requirements of relevant standards, and the surface water and groundwater concrete (structure) is corrosive, indicating the degree of influence on the project. This paper also provide a basis for the project to take protective measures and put forward protecting measures recommendations.
\end{abstract}

\section{Introduction}

The evaluation of the corrosion of environmental water on concrete (structures), steel bars and steel structures in reinforced concrete structures is one of the contents of the engineering survey. Therefore, the environmental water samples are taken during the survey to test the water chemical composition and the evaluation is carried out according to the specified requirements. From April 2019 to May 2020, during the pre-feasibility study phase of a hydropower station, 12 sets of water samples were taken in the dam site area to conduct indoor routine chemical composition tests, and the test results were passed to analyze the environmental water chemistry related to the project. Through the test results, analyze the environmental water chemistry characteristics related to the project, analysis of environmental water chemistry characteristics related to the project provides a basis for the project to take protective measures to prevent adverse effects on the project.

\section{Overview of the Geological Environment of the Dam Site}

A certain hydropower station is located on the middle reaches of the E River. According to the topographical conditions of the E River section, two selected dam sites are initially proposed in the $5 \mathrm{~km}$ section of the river, and the two dam sites are about $1.9 \mathrm{~km}$ apart. The arranged permanent main hydraulic structures include dams (concrete face rockfill dams), underground power generation systems, and spillway buildings (spill tunnels, spillways, etc.). The main temporary buildings are diversion tunnels, etc. The main permanent buildings are The material level is level 1 , the secondary building level is level 3 , the main hydraulic building structure level is level I, and the secondary building structure level is level II.

Bedrock gneiss or schistosity strikes $355^{\circ}-15^{\circ}$ in the dam site area. Taking the middle of the E river bed as the boundary, the left bank and the left side of the river bed incline near $\mathrm{E}$, with an inclination angle of $65^{\circ}-75^{\circ}$; The right bank and the right side of the river bed incline near $\mathrm{W}$, with an inclination of $70^{\circ}-80^{\circ}$. Faults and fissures are the main structural features in this area.Faults and fissures are the main structural features in this area. The faults mainly developed large-scale F. The faults are located on the left side of the riverbed and are $>15 \mathrm{~km}$ in length. They are regional faults and inactive faults. .

\section{Analysis on the characteristics of environmental water chemistry in dam site area}

Table 1. Testing result about chemical analysis of water in dam area

\begin{tabular}{|c|c|c|c|c|c|c|c|c|c|}
\hline $\begin{array}{l}\text { Type of water } \\
\text { sample }\end{array}$ & Sampling location & $\begin{array}{l}\text { Water } \\
\text { sample } \\
\text { number }\end{array}$ & anion content & cation content & $\begin{array}{l}\text { Free } \\
\mathrm{CO}_{2}\end{array}$ & $\begin{array}{c}\text { Erosive } \\
\mathrm{CO}_{2}\end{array}$ & $\mathrm{PH}$ & $\begin{array}{c}\text { Mineralizat } \\
\text { ion } \\
\text { degree }\end{array}$ & $\begin{array}{l}\text { Hydrochemical } \\
\text { types }\end{array}$ \\
\hline
\end{tabular}

*Corresponding author's e-mail: 2018302030124@whu.edu.cn 


\begin{tabular}{|c|c|c|c|c|c|c|c|c|c|c|c|c|c|c|}
\hline & & & \multirow{2}{*}{\multicolumn{11}{|c|}{ 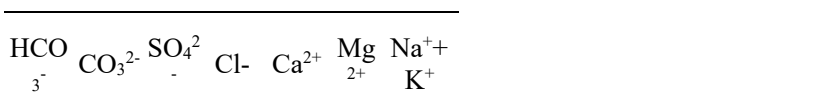 }} & \\
\hline & & & & & & & & & & & & & & \\
\hline & & & \multicolumn{4}{|c|}{$\mathrm{mg} / \mathrm{L}$} & \multicolumn{3}{|c|}{$\mathrm{mg} / \mathrm{L}$} & $\mathrm{mg} / \mathrm{L}$ & \multicolumn{2}{|l|}{$\mathrm{mg} / \mathrm{L}$} & \multicolumn{2}{|l|}{$\mathrm{mg} / \mathrm{L}$} \\
\hline \multirow{4}{*}{ Surface water } & $\begin{array}{l}\text { Gully on Left Bank } \\
\text { of lower dam site }\end{array}$ & SY01 & 53.1 & 0 & 1.9 & 7.8 & 8.4 & 3.7 & 10.3 & 15.9 & 8.5 & 7.07 & 85.2 & $\mathrm{HCO}_{3}-\mathrm{Ca}-\mathrm{Mg}-\mathrm{Na}$ \\
\hline & $\begin{array}{l}\text { Gully on Right Bank } \\
\text { of lower dam site }\end{array}$ & SY02 & 53.1 & 0 & 1.9 & 7.8 & 8.4 & 5.1 & 7.3 & 9.0 & 6.4 & 7.23 & 83.6 & $\mathrm{HCO}_{3}-\mathrm{Ca}-\mathrm{Mg}-\mathrm{Na}$ \\
\hline & $\begin{array}{l}\text { Upper dam site in the } \\
\text { middle of the river }\end{array}$ & SY03 & 17.7 & 0 & 1.9 & 7.8 & 10.4 & 0 & 0.7 & 7.0 & 6.4 & 6.96 & 38.6 & $\mathrm{HCO}_{3}-\mathrm{Cl}-\mathrm{Ca}$ \\
\hline & $\begin{array}{l}\text { The lower dam site is } \\
\text { in the middle of the } \\
\text { river }\end{array}$ & SY04 & 35.4 & 0 & 6.7 & 11.7 & 8.4 & 3.7 & 8.3 & 9.0 & 6.4 & 7.15 & 74.2 & $\begin{array}{c}\mathrm{HCO}_{3}-\mathrm{Cl}-\mathrm{Ca}-\mathrm{Mg}- \\
\mathrm{Na}\end{array}$ \\
\hline \multirow{2}{*}{ Groundwater } & $\begin{array}{l}\text { BK6 hole of upper } \\
\text { dam site (Confined } \\
\text { water) }\end{array}$ & SY05 & 40.9 & 0 & 6.7 & 9.6 & 6.4 & 2.4 & 14.0 & 63.7 & 60.5 & 6.33 & 80.0 & $\mathrm{HCO}_{3}-\mathrm{Cl}-\mathrm{Ca}-\mathrm{Na}$ \\
\hline & $\begin{array}{l}\text { ZK9 hole of lower } \\
\text { dam site (Confined } \\
\text { water) }\end{array}$ & SY06 & 53.1 & 0 & 17.3 & 9.6 & 12.4 & 3.9 & 14.0 & 79.6 & 69.8 & 6.35 & 110.3 & $\mathrm{HCO}_{3}-\mathrm{Ca}-\mathrm{Na}$ \\
\hline
\end{tabular}

During the investigation of a hydropower station in the Pre feasibility study stage, the dam site area is adopted 12 groups of environmental water (surface water and groundwater) samples were treated with indoor conventional hydration. The test results are shown in Table 1 , and the hydrochemical types are classified according to the separation.Anions and cations with more than $25 \%$ me /L content Ion group[1] .

The chemical composition of environmental water is the product of long-term interaction between water and environment (physical geography, geological background and human activities). In the dam site area and near-field area of the project, the rock and soil are mainly composed of metamorphic rock and part of magmatic rock (chemical composition mainly includes $\mathrm{SiO}_{2}, \mathrm{Al}_{2} \mathrm{O}_{3}, \mathrm{Fe}_{2} \mathrm{O}_{3}, \mathrm{FeO}$, $\mathrm{MgO}, \mathrm{CaO}, \mathrm{K}_{2} \mathrm{O}, \mathrm{Na}_{2} \mathrm{O}, \mathrm{H}_{2} \mathrm{O}, \mathrm{CO}_{2}, \mathrm{TiO}_{2}, \mathrm{P}_{2} \mathrm{O}_{5}$, etc.) and soil formed by weathering and transportation of bedrock. The chemical composition of water mainly comes from the weathering dissolution and chemical reaction process of rock and soil minerals in its environment, thus forming the specific chemical composition of surface water and groundwater in the dam site area. The groundwater is atmospheric precipitation and surface water through infiltration.In the process of migration, the content of chemical composition will change with the specific environment. In addition to the high content of free $\mathrm{CO}_{2}$ in groundwater and $\mathrm{HCO}_{3}$ - in confined water, the chemical composition of environmental water in the dam site area has general characteristics. The possible reasons for its high content are as follows[2]- [3]:

(1) The source of $\mathrm{CO} 2$ in groundwater is mainly formed by the oxidation of organic matter $(\mathrm{O} 2+\mathrm{CH} 2 \mathrm{O}=$ $\mathrm{CO} 2+\mathrm{H} 2 \mathrm{O}$ ), that is, by the respiration of plants and the fermentation of organic debris. This kind of action occurs in the atmosphere, soil and surface water, and the generated $\mathrm{CO} 2$ infiltrates into groundwater together with the infiltration water[4].

(2) In metamorphic rock and magmatic rock area, HCO3- and ions mainly come from weathering and dissolution of aluminosilicate minerals (such as
$\mathrm{Na}_{2} \mathrm{Al}_{2} \mathrm{Si}_{6} \mathrm{O}_{16}$ (albite) $+2 \mathrm{CO}_{2}+3 \mathrm{H}_{2} \mathrm{O} \rightarrow 2 \mathrm{HCO}_{3}{ }^{-}+2 \mathrm{Na}+$ $+\mathrm{H}_{4} \mathrm{Al}_{2} \mathrm{Si}_{2} \mathrm{O}_{9}+4 \mathrm{SiO}_{2} \cdot \mathrm{CaO} \cdot 2 \mathrm{Al}_{2} \mathrm{O}_{3} \cdot 4 \mathrm{SiO}_{2}$ (anorthosite) $\left.+2 \mathrm{CO}_{2}+5 \mathrm{H}_{2} \mathrm{O} \rightarrow 2 \mathrm{HCO}_{3}{ }^{-}+\mathrm{Ca}^{2+}+2 \mathrm{H}_{4} \mathrm{Al}_{2} \mathrm{Si}_{2} \mathrm{O}_{9}\right)$. There are three main sources of $\mathrm{HCO}_{3}{ }^{-}$in confined water: (1) $\mathrm{HCO}_{3}{ }^{-}$formed by weathering and dissolution of superficial aluminosilicate minerals is carried from recharge source to provide part of confined water through downward seepage water. (2) In the process of water migration in the runoff channel, a small part of the water is provided by the dissolution of aluminosilicate minerals in the rock mass near the runoff channel.

\section{Evaluation on the corrosiveness of environmental water to concrete and its influence on the project}

\subsection{Corrosivity evaluation}

When the content of $\mathrm{HCO}_{3}{ }^{-}, \mathrm{H}^{+}$and corrosive $\mathrm{CO}_{2}$ in the environmental water is at the limit value, the concrete will be carbonated, or the cement stone will be hydrolyzed, so that $\mathrm{Ca}(\mathrm{OH})_{2}$ in the cement stone will be neutralized, or $\mathrm{CaO}, \mathrm{Ca}(\mathrm{OH})_{2}$ and other components will be dissolved and continuously lost, which will gradually reduce the alkalinity of concrete, and then cause the reduction of concrete strength. Content of $\mathrm{Cl}^{-}$and $\mathrm{SO}_{4}{ }^{2-}$ in environmental water[5]. When it reaches a certain value, the passivation effect of steel bar or steel structure in reinforced concrete structure will be lost, which will cause corrosion of steel bar and expansion of corrosion material of steel bar.

According to the test results of indoor conventional water chemical composition of environmental water in the dam site area of the hydropower station, the corrosivity of environmental water to concrete (structure), reinforcement in reinforced concrete structure and steel structure is determined respectively according to the evaluation standards of $\mathbb{C}$ Code for geological 
investigation of water conservancy and Hydropower Engineering 》( $G B$ 50287) and 《Codefor investigation of geotechnical engineering 》 (GB 50021).

Code for geological investigation of water conservancy and Hydropower Engineering (GB 50287).According to the standard of GB 50287, the corrosion of environmental water to concrete is evaluated on the basis of $\mathrm{HCO}_{3}{ }^{-}$content, $\mathrm{pH}$ value, corrosive $\mathrm{CO}_{2}$ content, $\mathrm{Mg}^{2+}$ content and $\mathrm{SO}_{4}{ }^{2-}$ content. According to this standard, the evaluation and judgment of environmental water corrosivity to concrete are shown in Table 2, and the basis of no corrosivity to concrete is not listed. It can be seen from the judgment result table that the Gully Water on the left and right bank of the lower dam site in the surface water has decomposition dissolution weak to medium corrosivity to the concrete; the river water on the upper and lower dam sites has decomposition dissolution medium corrosivity to the concrete; the borehole groundwater on the bank slope of the upper and lower dam sites has decomposition dissolution weak to medium corrosivity to the concrete, general acid weak corrosivity and carbonic acid strong corrosivity.The results show that the confined water in the river bed has no decomposition corrosion to the concrete. Surface water (gully water, river water) and groundwater have no crystal and decomposition crystal compound corrosivity to concrete.

Table 2. Evaluation on corrosiveness which environment water in dam area to the concrete

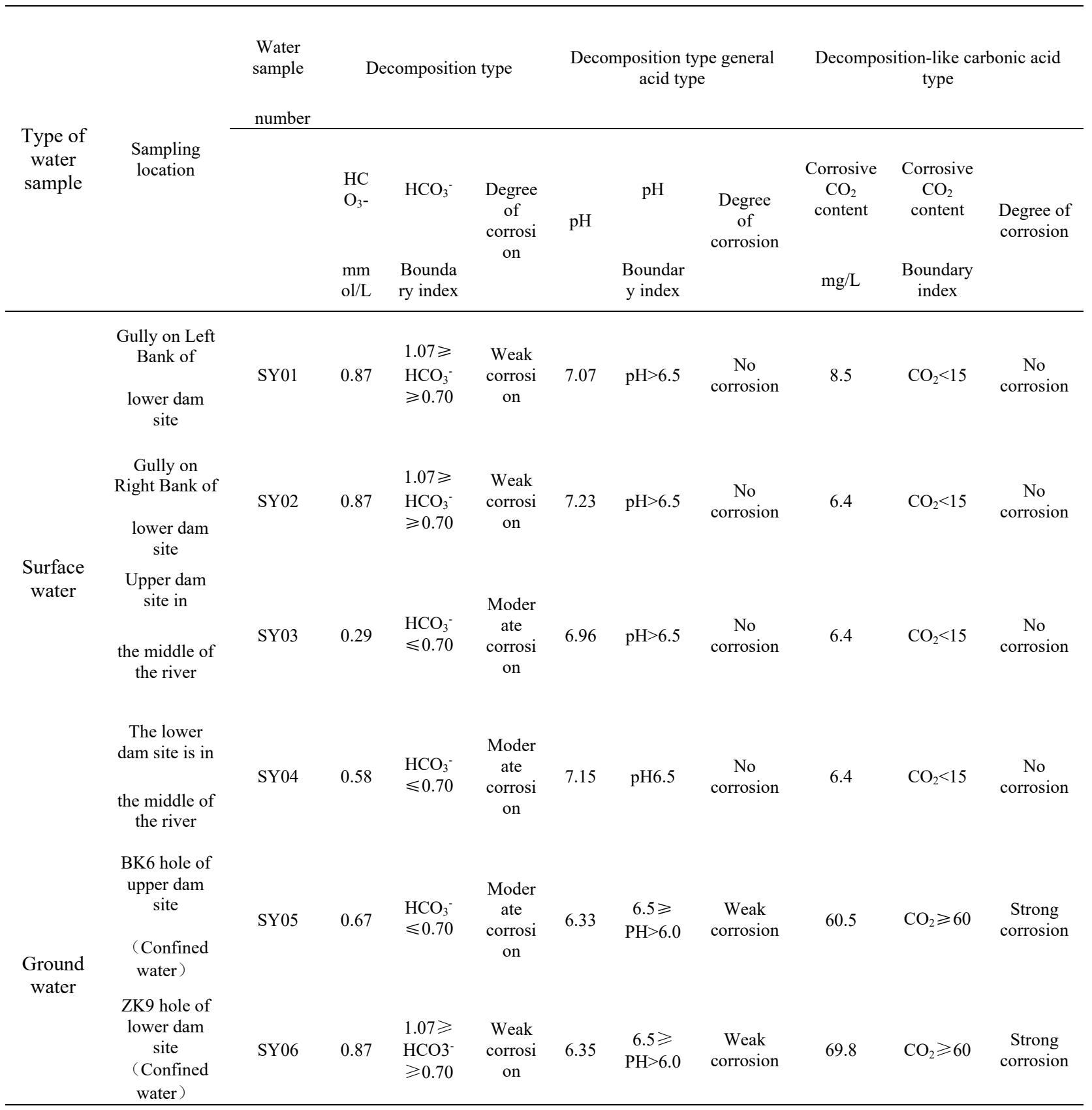

Therefore, it can be judged that the surface water in the dam site area has weak to medium corrosivity to the concrete; the groundwater in the bank slope (perched water and phreatic water in the upper layer) has weak to 
strong corrosivity to the concrete, except that the confined water in the riverbed has no corrosivity to the concrete.

To sum up, the comprehensive evaluation shows that the surface water in dam site area has great influence on concrete(structure) has weak to medium corrosivity; groundwater has weak to strong corrosivity to concrete (structure). In the environmental water, there is no corrosivity except that the confined water in the riverbed has moderate corrosivity to the reinforcement in the reinforced concrete structure. The confined water in the riverbed of the environmental water is moderately corrosive to the steel structure, and the rest is weakly corrosive.

\subsection{Impact on the project}

The corrosiveness of environmental water to concrete will make its strength (compression) and durability gradually decrease or even weaken to loss without protection, which is a long-term process. The corrosive effect of environmental water on steel bars and steel structures in reinforced concrete structures is similar to that on concrete.

Concrete and reinforced concrete structural materials will be used in the dam face slab and toe slab, underground power plant, diversion tunnel and tailrace tunnel, spillway, sluice dam of spillway control section, diversion tunnel and cofferdam of temporary buildings; steel structural materials will be used in diversion tunnel, spillway, sluice dam and diversion tunnel. According to the comprehensive evaluation results, the environmental water in the dam site area has weak strong corrosivity to the concrete (structure) of the above buildings and weak corrosivity to the steel structure. Therefore, the environmental water will have adverse effects on the project and bring hidden dangers to the permanent safety of the project, so protective measures should be taken.

\section{References}

1. Chen, A., Wu, M., Chen, K. Q., Sun, Z. Y., Shen, C., \& Wang, P. Y. (2016). Main issues in research and p ractice of environmental protection for water conser vancy and hydropower projects in China. Water Scie nce and Engineering, 9(4): 312-323.

2. Yang, J., Yao, C., Liu, C., JIANG, S., \& LI, H. (2017 ). Exploration on virtual simulation practice teaching for the major of water conservancy and hydropower engineering. Journal of Architectural Education in In stitutions of Higher Learning, 26(5): 134-137.

3. Zhao, L., Liu, X., Mao, J., Xu, D., Munjiza, A., \& A vital, E. (2018). A novel discrete element method ba sed on the distance potential for arbitrary 2D convex elements. International Journal for Numerical Metho ds in Engineering, 115(2): 238-267.

4. Sun, Y., Wan, J., Yang, S., Xue, X., \& Huang, K. (20 16). Influences of water conservancy and hydropowe $r$ projects on runoff in Qingjiang River Upstream $\mathrm{Ba}$ sin. Journal of Earth Science, 27(1): 110-116.

5. Hegao, W. U., Jinhong, Y. U., Changzheng, S. H. I., \& Huidan, S. H. I. (2020). Discussion on some probl ems in design of buried steel pipe for water conserva ncy and hydropower industry. YANGTZE RIVER, 5 1(8): 141. 